\title{
Consumers Gain Equivalent Levels of Happiness from Sharing about an Experience and an Object
}

\author{
Wilson Bastos
}

Assistant Professor of Marketing; CATÓLICA-LISBON School of Business \& Economics, Palma de Cima, 1649-023 Lisbon, Portugal; email: wilson.bastos@ucp.pt.

The author expresses gratitude to Ana Bianchi de Aguiar, Daniel Fernandes, Sarah Moore, and Tania Sales for their helpful input on prior versions of the manuscript.

Funding: This work was supported by the FCT-Portuguese Foundation of Science and Technology. 


\title{
Consumers Gain Equivalent Levels of Happiness from Sharing about an Experience and an Object
}

\begin{abstract}
Purpose - To examine how conversing about experiences and objects affects consumer happiness. In contrast to previous research focusing on the conversation frequency, this paper explores how each conversation instance influences happiness.

Design/methodology/approach - Four experiments employ three different methodologies: actual talking behavior (Study 1), recalled and mental framing interventions and measurement of the focal variables (Studies 2 and 3), and manipulation of purchase conversationality (Study 4). Findings - Consumers derive equivalent levels of happiness from each material or experiential conversation they have. When the object is highly conversational (when it generates as much conversation as experiences do), it advances as much happiness as experiences.

Research implications - The findings inform precisely how the purchase conversationality model unfolds; clarify previous claims made in the literature; establish the direction of causal effect; and reveal a novel boundary condition of happiness superiority of experiences.

Practical implications - The findings inform marketing managers how to optimally allocate their WOM resources in order to advance consumer happiness. Additionally, this work shows a mental framing strategy able to increase WOM for objects-i.e., a tool for the manager.

Originality/value - This is the first investigation to disentangle frequency of conversation from each conversation's ability to advance happiness. It is also the first to engage participants in an actual conversation and measure changes in their happiness, and therefore conclusively establish the direction of the effect. Additionally, by manipulating purchase conversationality, this work demonstrates a new boundary condition associated with conversationality.
\end{abstract}

Keywords: experiences; objects; word-of-mouth; happiness 
Firms have become increasingly aware of the importance of word-of-mouth (WOM) for both experiences (Filo et al., 2015; Gelper et al., 2018; Romaniuk and Hartnett, 2017) and material products (Babie Rosario et al., 2016; Consiglio et al., 2018; Packard and Berger, 2017); and they have invested in innovative and costly campaigns to encourage consumers to talk about their purchases (Sweeney et al., 2012). Indeed, firms have much to gain from WOM; after all, when consumers talk about their experiences and objects, the shared content tends to propagate widely (Mangold and Faulds, 2009) and to be perceived as credible (Ahrens et al., 2013; Huang and Chen, 2006), which make WOM a powerful tool to engender product adoption (Roy et al., 2019). However, recent research has found that WOM also influences how consumers feel about their purchases and the benefits they gain from them (Jones et al., 2014). This investigation focuses on a specific psychological benefit of WOM conversations: consumer happiness.

Making consumers happy has long been a primary objective for many firms (Anderson et al., 1994) and a topic of interest for academics (Opree et al., 2016). It is therefore relevant that research provides the marketing manager with tools that can help in that regard.

Recent WOM research has found an association between WOM conversations and consumer happiness - a finding consistent with the general relationship between leisure activities, such as socializing, and happiness (Yang et al., 2013). Evidence from WOM research suggests that telling others about one's purchases increases the consumer's own happiness. Specifically, findings indicate that consumers talk more frequently about their experiences than their objects, and this greater conversationality explains why experiences advance happiness more than do objects (Figure 1; Bastos and Brucks, 2017; Kumar and Gilovich, 2015). This finding suggests that the effect responsible for the conversationality mechanism resides on the left side of the model depicted on Figure 1-i.e., the effect of purchase type on conversationality. 
Albeit informative, this finding allows for two competing possibilities: First, experiences get talked about more often than objects (as demonstrated by Bastos and Brucks [2017] and Kumar and Gilovich [2015]), but when people do converse about the two purchase types they gain similar levels of happiness. If supported empirically, this first possibility would indicate that firms can help consumers gain more happiness from their objects, perhaps as much as they gain from their experiences, by motivating them to converse more frequently about those objects. However, an important condition must be met for this to hold: That a conversation about an object and one about an experience are similarly able to advance consumer happiness. This condition is critical because, besides generating more conversations, it is possible that experiences also create conversations that advance more happiness than do objects. If supported, this second possibility would indicate that the marketing manager deciding whether to allocate WOM resources towards increasing WOM for material or experiential purchases would have a greater impact on consumer happiness by motivating consumers to share about their experiences, instead of their objects.

This investigation examines which of these two possibilities attains empirical support. In doing so, it aims to provide a more precise understanding of how the conversationality model unfolds - a contribution to theory—and help managers optimally allocate WOM resources when the goal is to increase consumer happiness - a contribution to practice. Naturally, this knowledge can also guide consumers on which type of WOM offers them greater happiness potential — thus, the findings also have social value.

Figure 1. Purchase Conversationality Model 


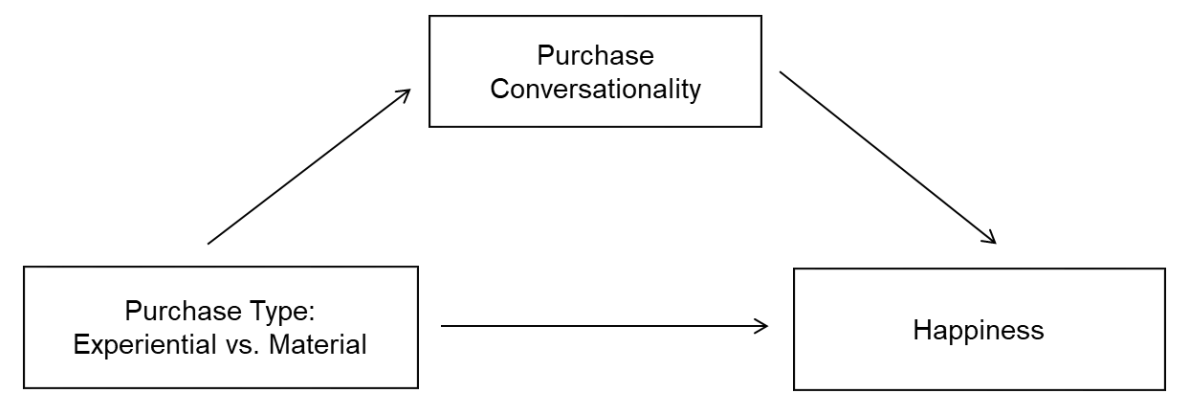

Thus far, it is still an unstudied question what happens to happiness each time consumers converse about an experience or an object. This question focuses on whether the effect of conversationality on happiness is qualified by the type of purchase, the right side of the model shown on Figure 1. Of note, this question relates to the ability of each conversation to cultivate happiness, which distinguishes this investigation from previous works examining conversation frequency (Bastos and Brucks, 2017; Kumar and Gilovich, 2015).

Previous research holds that conversing about an experience appears more beneficial for happiness than conversing about an object (Kumar and Gilovich, 2015). Although intuitively appealing, this idea lacks direct empirical evidence. Specifically, Kumar and Gilovich reported that participants attributed a higher proportion of their experience-derived happiness to talking, as compared to their object-derived happiness. This is plausible since, as their and Bastos and Brucks' (2017) data show, an experience is likely to be talked about more often than an object. Thus, considering the greater quantity of conversations that an experience generates, it is reasonable that talking accounts for a greater proportion of the happiness an experience (vs. an object) provides. However, research has not yet studied whether consumers gain more happiness when they tell people about an experience versus an object.

Although the existing literature points to the two possibilities discussed earlier, it is unclear which possibility is more likely to emerge. Since prior work in the conversationality of experiential and material purchases has not yet examined each conversation's ability to advance 
happiness, the literature lacks firm theoretical grounds on which one could theorize, ex-ante, for either of the two possibilities. Instead of engaging in HARKing (Hypothesizing After the Results are Known-Kerr, 1998) — a practice that is increasingly gaining attention for its potential harm to scientific progress (Crano et al., 2014; Pieters, 2017; Rubin, 2017) — neutral stance. Specifically, it discusses, in depth, the theoretical rationale for each of the two possibilities and lets the empirical evidence point to the answer. This non-HARKing approach offers transparency since it is open to the possibility of competing or unexpected results, including those that do not reach the conventional levels of statistical significance, and, albeit informative, tend to go unreported otherwise, leading to the "file drawer problem" (Rosenthal, 1979, p. 638).

Understanding the ability of different types of conversations to advance consumer happiness is relevant and consequential. That is, irrespective of which possibility obtains empirical support, the findings from this investigation will inform the level of happiness consumers gain from conversing about two topics common in WOM conversation (objects and experiences). This finding will add to theory by either confirming or clarifying claims made in the literature (Kumar and Gilovich, 2015) and will inform practice by helping managers and consumers make decisions associated with WOM.

This manuscript is organized as follows: First, it theorizes for the two possible outcomes. Next, it reports four studies indicating that conversing about an experience or an object are

\footnotetext{
${ }^{1}$ HARKing is problematic to science because it involves including post hoc hypotheses that are always confirmed by the data and/or removing a priori hypotheses that fail to obtain support from the data. This, in turn, precludes reports of falsification, an essential part of the scientific process (Popper, 1959). In a similar vein, the practice of HARKing increases the odds of falsely rejecting null-hypotheses (type I error; Rubin, 2017). Because it is based on an inspect-and-select strategy, HARKing has been considered a "practice that could compromise the validity of social research" (Crano et al., 2014, p. 356) and that "renders statistical testing meaningless" (Pieters, 2017, p. 694).
} 
equally beneficial for consumer happiness. In closing, the manuscript elaborates on the theoretical and practical implications of the findings, their limitations, and opportunities for future inquiries.

\section{Theoretical Background}

This section is divided in two parts. Each part draws on interpersonal conversation and WOM research to build the rationale for the two competing hypotheses tested here. The first part argues that conversing about an experience or an object advance similar levels of happiness; whereas the second argues that conversing about an experience is more beneficial for happiness than conversing about an object. A possible third hypothesis would be that conversing about an object (vs. experience) generates more happiness, however this idea is inconsistent with previous frameworks (e.g., Bastos and Brucks, 2017) and therefore will not be considered here.

\section{Similar Happiness Gains from Both Conversation Types (Experiential and Material)}

If the ways that verbal interactions increase happiness are applicable to conversations about experiences and objects, these two conversation types should be similarly able to advance happiness. Past theorizations about the positive outcomes that people obtain from conversinge.g., confirmation, learning, salience in memory — support this notion (Berger, 2014). Specifically, talking about a purchase of either type (experiential or material) may allow the teller to obtain confirmation of a wise purchase (Gatignon and Robertson, 1986). Further, the conversation might enable the teller to learn about ways to better interpret the experience and better use the object (Bandura, 1977). Additionally, "the communicative act may involve rehearsal and elaboration, both of which seem likely to prolong and enhance the [benefits of the purchase] by increasing its salience" in memory (Gable et al., 2004, p. 229). This can be positive for both purchase types as it helps keep the events forming the experience fresh in one's memory (Langston, 1994) and reduces the effect of adaptation commonly associated with objects 
(Nicolao et al., 2009). Thus, the ways verbal interaction advances happiness appear functional for conversations about experiences as well as those about objects, suggesting that the two conversation types may be similarly able to cultivate happiness.

In addition, material purchases possess specific positive attributes that might contribute to material conversations' ability to increase happiness, perhaps as much as experiential conversations. Previous research points to the beneficial role of mental accessibility in purchaserelated conversations (Berger and Schwartz, 2011), and recent, preliminary evidence indicates that people find it easier to come up with something to share about an object than an experience (Bastos and Brucks, 2017). Indeed, the tangibility of objects allows one to refer to it during the conversation and obtain information or illustrate a point. This facility in the conversation may contribute to the level of happiness that the conversation is able to advance.

The tangibility of objects (vs. experiences) may also allow for a fuller absorption of the purchase as more of the human senses can capture it (e.g., sight, touch; Krishna, 2012); likely increasing engagement in the conversation (Altman and Taylor, 1973). Participating in engaging conversations is one of people's most treasured daily activities (Csikszentmihalyi and Larson, 1987) and previous evidence indicates that involving and deep conversations are associated with greater happiness in life (Mehl et al., 2010). In this sense, objects' ability to create captivating interactions may prove beneficial for itself, in that people might associate the positivity of the conversation with the happiness the object provides them. Hence, it is possible that conversing about an object is as beneficial for happiness as conversing about an experience. Formally put, the first of the two competing hypotheses is:

Hypothesis 1: Conversing about an experience or an object are similarly beneficial for happiness. 


\section{Larger Happiness Gains from Experiential (vs. Material) Conversations}

Despite these positive attributes of objects, research has shown that experiences are superior on some aspects, which could potentially make experiential conversations a greater source of happiness. Compared to objects, experiences are more representative of the self, thus allowing for more self-disclosure (Carter and Gilovich, 2012) — a conversation aspect known to engender psychological benefits for the person sharing the information (Collins and Miller, 1994). Further, experiences are more unique (Rosenzweig and Gilovich, 2012) and less prone to invidious comparisons (Carter and Gilovich, 2010), which should lead to more interesting and harmonious conversations. Also, because they live in one's memories, experiences are prone to favorable reconstruction over time (the "rosy view" phenomenon; Mitchell et al., 1997). In turn, those increasingly positive memories are likely afford conversation content of the type that is beneficial for happiness. Objects, on the other hand, have their own external existence. They exist in the here and now, and their tangibility leaves little room for favorable reinterpretation beyond what they truly are.

Additionally, because they have a beginning, middle, and end, experiences are particularly amenable for storytelling (Van Boven and Gilovich, 2003), potentially leading to involving conversation interactions (Escalas, 2006). Indeed, evidence from actual conversations indicates that people report enjoying more and building stronger relationships in conversations about experiences than in those about objects (Van Boven et al., 2010, Study 5). These positive attributes of experiential (vs. material) interactions may imbue them with a superior capacity to increase happiness. Hence, it is possible that talking about an experience advances happiness more than talking about an object. Formally stated, the second of the two competing hypotheses is: 
Hypothesis 2: Conversing about an experience is more beneficial for happiness than conversing about an object.

\section{Studies Overview}

This paper reports results from four studies. Study 1 engages participants in an actual face-to-face conversation. It manipulates the behavior of talking about the purchase (object vs. experience) or an unrelated topic (control) to examine the degree to which conversing about each purchase type increases happiness, as compared to the control conditions. Next, Studies 2 and 3 adopt, respectively, recall and framing procedures that have been used extensively by past work in this research domain. This approach allows the present investigation to examine conversations' ability to advance happiness in light of that work. These two studies (i.e., 2 and 3) measure the conversation construct the same way it was measured in previous research (Bastos and Brucks, 2017) and test, via moderation analysis, whether the magnitude of its effect on consumer happiness differs between material and experiential purchases. Last, Study 4 manipulates conversationality to equalize material and experiential purchases on that dimension and examine whether, when both purchases have equally high conversationality, they advance similarly high levels of happiness - thus eliminating the happiness superiority of experiences.

\section{Study 1-Actual Conversation}

Study 1 tests whether experiential and material conversations lead to similar (Hypothesis 1) or different increases in consumer happiness (Hypothesis 2). It does so by engaging participants in talking about a purchase and assessing happiness. The study randomly assigned participants to recall and write down either a material or an experiential purchase. Critically, participants were later randomly assigned to talk about either the purchase they had recalled (experimental condition) or an unrelated topic (control condition). This experimental design allows for the examination of 1) whether people who share about the purchase (vs. unrelated 
topic) report gains in happiness, and, more important, 2) how large these gains are for each purchase type (material vs. experiential). Study 1 assesses happiness across all participants both before and after they share, and focuses the statistical analysis on the change in happiness at the individual level (post-sharing minus pre-sharing happiness).

\section{Procedures}

Pilot study. Prior to conducting Study 1, the author ran a pilot study to gain an understanding of the amount of time people normally converse about purchases. In the pilot study, 34 participants from the same population as Study 1's recalled and shared with another participant about either a material or an experiential purchase they had made in the past. Participants were informed that they were free to converse for as long as they wished.

An independent rater listened to the voice recordings of each conversation and reported how long participants conversed about the purchase. Across the two purchase type conditions (material vs. experiential), participants conversed about the purchase for an average of 137.48 seconds $(S D=113.64)$. Importantly, material $(M=140.56, S D=115.15)$ and experiential participants conversed for equivalent lengths $(M=134.59, S D=115.33 ; F(1,31)=0.02, p=.88$, Cohen's $d=0.05$ ). These results indicate that imposing a time constraint on the conversation (Cooney et al., 2017) would not differentially affect conversations about experiences versus objects. To help keep participants on task in the main study ${ }^{2}$, a time limit of 2:30 minutes was thus established for conversations in Study 1 -a time duration just above the observed average in the pilot study-i.e., 2:17 minutes.

\footnotetext{
${ }^{2}$ Pilot study participants spent the majority of their time talking about topics unrelated to the task, and often discussed the study itself. This prompted the idea of imposing a time constraint in the main study. In the pilot study, the complete interaction (i.e., purchase-specific plus other topics that participants decided to converse about) lasted similar amounts of time between conditions $(M$ mat $=645.56, S D=134.61$ vs. $M \exp =623.82, S D=171.13 ; F(1,31)$ $=0.16, p=.68$, Cohen's $d=0.14$ ).
} 
Study 1. The study employed a 2 (purchase type: material vs. experiential) by 2 (conversation topic: the purchase vs. an unrelated topic) between-subjects design. One hundred and ninety-nine undergraduate students from a large American state university participated for class credit. Of the 97 participants assigned to the role of a teller (vs. conversation partner), 23 were female. Data from all 97 participants were used in the analyses_only the data from tellers (vs. conversation partners) are relevant for and thus reported in the present work.

Upon arrival at the lab, participants (maximum of 20 per session) received one of the two versions of a questionnaire. Without yet making it explicit to participants, this procedure randomly assigned them to the role of sharing about something (herein called tellers) or being a conversation partner. All participants were then instructed to complete their questionnaires. While the conversation partners completed filler questions, the tellers were asked to recall and write down either an object or an experience they had purchased in the last 12 months for about \$50. A 6-inch line was provided for that, and participants were asked to "Put your answer on the line above." This procedure was intended to restrict the amount of writing about the purchase, which, if unrestricted, could be interpreted as a (written) sharing instance. During this phase of the study, all participants were kept unaware of the upcoming conversation activity to ensure that the purchase the tellers recalled was not influenced by the knowledge that they would potentially tell somebody about it later.

Next, all tellers completed a two-item measure of (pre-sharing) happiness adapted from previous research in this domain: "When you think about that object/experience, how happy does it make you?", "How much does that object/experience contribute to your happiness in life?" (1 $=$ Not at All; $7=$ Very Much; $r=.48, p<.001 ;$ Van Boven and Gilovich, 2003), and filler questions so to attenuate participants' awareness of the study's focus on happiness. 
Next, tellers and conversation partners were separated. Tellers were instructed that they would soon be paired with one of the participants who had gone to the other conference room, and that they would converse about a topic that the teller would later be given. Tellers were instructed to be spontaneous and to talk about the topic as if they were conversing with a friend.

Simultaneously, in a separate conference room, participants with the role of conversation partners were verbally given similar instructions about the upcoming conversation activity (please see Web Appendix A for the complete instruction texts). The instructions intended to ensure that bi-directional (vs. one-way) conversations would take place, resembling the interactions that normally happen when people converse.

Following, participants were randomly paired up (but within gender, when possible, to increase the likelihood of common purchasing interests). In the cases when no-shows created an odd number of participants, two conversation partners were assigned to one teller (this occurred in five instances). Before starting the conversation activity, the pairs were instructed to engage in an ice-breaking activity where they would tell each other their names, majors, and something interesting about themselves. This activity was intended to get participants acclimated with the idea of conversing. Next, the pairs were told that there would be a time limit for the conversation activity (the specific amount of time was not announced to participants in order to avoid the possible distraction of clock-checking) and that they would be informed of its end with a sound signal (the sound of hand clapping). Then, independently, tellers were randomly assigned to talk about either the purchase they had just written down or a control subject (doing laundry; a neutral and familiar topic that involves both an activity and an object). Next, each pair was let into an individual room and all pairs were simultaneously instructed to close the door and start the conversation. 
When time for the conversation activity was up, the tellers and their conversation partners were again separated. The tellers independently answered a survey with the dependent variable measure- the same two items on (post-sharing) happiness $(r=.58, p<.001)$. Last, all participants were thanked, debriefed, and released.

To assess the effects of conversation topic (purchase vs. unrelated topic) and purchase type (material vs. experiential) on changes in happiness, the author first computed a difference score by subtracting pre-sharing happiness from post-sharing happiness (i.e., post minus pre). The author then performed a 2-way ANOVA with conversation topic and purchase type as independent variables, and the difference score for happiness as dependent variable. This analysis is suitable for this study's purposes because any value above (below) the zero value indicates gains (losses) in happiness relative to its starting point. Of note, the results reported below are robust to analytical method, as a repeated-measures ANOVA as well as an ANCOVA controlling for pre-sharing happiness yielded the same conclusions.

\section{Results}

Analysis of Moderation. An ANOVA showed that the difference score for happiness is significantly higher for participants who shared about the purchase $(M=0.23, S D=1.03)$ versus the unrelated topic $(M=-0.13, S D=0.77 ; F(1,93)=3.93, p=.050, \eta 2=.04)$. Non-significant results are observed for both the main effect of purchase type $\left(M_{\text {mat }}=0.03, S D=0.90 \mathrm{vs}\right.$. $M_{\exp }=$ $0.07, S D=0.95 ; F(1,93)=0.07, p=.78, \eta 2=.001)$ and, importantly, the interaction $(F(1,93)=$ $0.10, p=.74, \eta 2=.001 ;$ please see Table 1 for ANOVA results in tabular form). Among participants who shared about the purchase (experimental condition), the difference score for the experiential $(M=0.29, S D=1.06)$ and the material purchase conditions are statistically indistinguishable $(M=0.18, S D=1.01 ; F(1,47)=0.14, p=.70$, Cohen's $d=0.10$; see Web 
Appendix B for additional statistics on pre- and post-sharing happiness). Supporting Hypothesis

1, these results show that sharing about an experience or an object advance happiness similarly.

Table 1

Effect of Conversation Topic x Purchase Type on the Difference Score for Happiness-Study 1

\begin{tabular}{lccccc}
\hline Factor & SS & df & MS & $F$ & $p$ \\
\hline Conversation Topic & 3.33 & 1 & 3.33 & 3.93 & .05 \\
Purchase Type & 0.06 & 1 & 0.06 & 0.07 & .78 \\
Interaction & 0.08 & 1 & 0.08 & 0.10 & .74 \\
Error & 78.76 & 93 & 0.84 & & \\
& & & & & \\
\hline
\end{tabular}

\section{Discussion}

Study 1 shows that the behavior of talking about experiential and material purchases is a productive way of cultivating consumer happiness, and central to the present work, sharing about the two purchase types leads to equivalent gains in happiness.

The author acknowledges that the effect size for conversation topic is small $(\eta 2=.04)$, but argues that a small effect is expected because it was based on a single sharing occasion involving an unfamiliar conversation partner. These factors likely minimized the impact of conversing on happiness. In a natural environment, sharing with friends may provide more benefits than can be observed in the lab (Lyubomirsky et al., 2005).

Because work in this research stream relied on analysis of mediation (Bastos and Brucks, 2017; Kumar and Gilovich, 2015), their correlational evidence leaves open the possibility of reverse causality (Spencer et al., 2005). By experimentally manipulating the topic of conversation and measuring happiness, Study 1 complements past work by being the first to conclusively establish the direction of the effect-i.e., conversation $\rightarrow$ happiness. 
Next, Studies 2 and 3 seek a different type of evidence by employing experimental approaches previously used this research domain: recall and framing approaches. Specifically, they randomly assign participants to condition (experiential vs. material purchase) and assess both purchase conversationality and happiness. This procedure is suitable for the present investigation because it allows for analysis of moderation examining whether the effect of conversationality on happiness differs by purchase type. Hypothesis 1 will be supported if the relationship between conversationality and happiness is independent of purchase type, whereas Hypothesis 2 will be supported if that relationship is qualified by purchase type.

\section{Study 2-Recalled Purchase}

Study 2 employs a recall-based approach to examine the level of happiness resulting from the conversationality of experiences and objects.

\section{Procedures}

One hundred Amazon Mechanical Turk (Mturk) participants completed the study for financial compensation ( $63 \%$ females; $\left.M_{\text {age }}=35.54, S D=12.35\right)$. Randomly assigned participants recalled and described the most recent occasion when they had spent about $\$ 50$ on either an object or an experience (Van Boven and Gilovich, 2003). Next, they answered a fiveitem measure of conversationality (e.g., "I desire to talk to people about my experience/object"; $1=$ Strongly Disagree $; 7=$ Strongly Agree $; \alpha=.95 ;$ Bastos and Brucks, 2017), the same two-item measure of happiness used in Study $1(r=.69, p<.001)$, and a three-item manipulation check measure (e.g., "In my view, the purchase I described earlier is: 1 = Definitely a material object; 7 $=$ Definitely an event or an activity; $\alpha=.93$; see Web Appendix $\mathrm{C}$ for the complete manipulation text and measurement items). The manipulation was successful: Experiential participants perceived the purchase as more experiential $(M=6.16, S D=1.05)$ than did material participants 
$(M=1.76, S D=1.09 ; t(98)=20.41, p<.001$, mean difference $=4.40,95 \%$ confidence interval

[CI] [3.97, 4.83], Cohen's $d=4.11$; see Table 2 for ANOVA results in tabular form).

Table 2

Manipulation Check of Purchase Type (ANOVA)—Study 2

\begin{tabular}{lccrcc}
\hline Factor & SS & df & MS & $F$ & $p$ \\
\hline Purchase Type & 483.83 & 1 & 483.83 & 418.00 & $<.001$ \\
Error & 113.43 & 98 & 1.15 & & \\
\hline
\end{tabular}

\section{Results}

Analysis of Moderation. Study 2 aimed to reexamine whether conversations centered on an experience differ from those centered on an object in their ability to advance happiness. As in past work, Study 2 assessed the conversation construct with the measure of purchase conversationality (Bastos and Brucks, 2017), and the current analysis tested whether the effect of conversationality on happiness varies by purchase type. Thus, this analysis of moderation (PROCESS, model 1, with 10.000 resamples) treated conversationality as the independent variable, happiness as the dependent variable, and purchase type (experiential vs. material) as the potential moderating variable. Results indicated that conversationality has a significant and positive effect on happiness for objects $(\beta=0.49, S E=0.11, t(96)=4.30, p<.001,95 \% \mathrm{CI}=$ $[0.26,0.71])$ and a marginal and positive effect for experiences $(\beta=0.23, S E=0.12, t(96)=$ $1.78, p=.07,95 \% \mathrm{CI}=[-0.02,0.48])$. Important, the magnitudes of these two effects are statistically indistinguishable $(\beta=-0.26, S E=0.17, t(96)=-1.53, p=.12,95 \% \mathrm{CI}=[-0.60$, 0.07]), supporting Hypothesis 1.

The author advances that the finding that material and experiential conversations generate statistically equivalent levels of happiness replicated in Studies 3 and 4, as well as in seven 
unreported studies (see Table 3 for a summary of these replications and Web Appendix E for details on each of the seven studies). Of note, these replication studies employed a variety of approaches across three substantially different sample populations: American undergraduate students, European Masters level business students, and online samples of American and Canadian individuals. Additionally, and in line with these findings, a single-paper meta-analysis across the 11 studies yielded significant effects of both material $(r=.40, S E=0.03,95 \% \mathrm{CI}=$ $[0.33,0.47])$ and experiential conversations on happiness $(r=.37, S E=0.03,95 \% \mathrm{CI}=[0.30$, $0.44]) ;$ and these effects are statistically indistinguishable $(r=-.03, S E=0.02,95 \% \mathrm{CI}=[-0.07$, $0.01])^{3}$, a finding that adds substantial support for Hypothesis 1 .

Table 3

Summary of Results from Seven Replication Studies

\begin{tabular}{|c|c|c|c|}
\hline Studies & $\begin{array}{c}\mathrm{CV} \rightarrow \text { Happiness (Material } \\
\text { Purchase) }\end{array}$ & $\begin{array}{c}\mathrm{CV} \rightarrow \text { Happiness } \\
\text { (Experiential Purchase) }\end{array}$ & $\begin{array}{l}\text { Interaction of CV x } \\
\text { Purchase } \rightarrow \text { Happiness }\end{array}$ \\
\hline$(\mathrm{N}=95)$ & $\begin{array}{c}\beta=0.46, \mathrm{SE}=0.11, \mathrm{t}(91)= \\
4.18, p<.001,95 \% \mathrm{CI}= \\
{[0.24,0.67]}\end{array}$ & $\begin{array}{c}\beta=0.26, \mathrm{SE}=0.12, \mathrm{t}(91)= \\
2.07, p=.04,95 \% \mathrm{CI}= \\
{[0.01,0.51]}\end{array}$ & $\begin{array}{c}\beta=-0.09, \mathrm{SE}=0.08, \mathrm{t}(91)= \\
-1.16, p=.24,95 \% \mathrm{CI}= \\
{[-0.53,0.13]}\end{array}$ \\
\hline $\begin{array}{l}\text { Study } 2 \\
(\mathrm{~N}=67)\end{array}$ & $\begin{array}{c}\beta=0.26, \mathrm{SE}=0.13, \mathrm{t}(63)= \\
1.94, p=.05,95 \% \mathrm{CI}= \\
{[-0.006,0.54]}\end{array}$ & $\begin{array}{c}\beta=0.48, \mathrm{SE}=0.15, \mathrm{t}(63)= \\
3.21, p=.002,95 \% \mathrm{CI}= \\
{[0.18,0.78]}\end{array}$ & $\begin{array}{c}\beta=0.10, \mathrm{SE}=0.10, \mathrm{t}(63)= \\
1.05, p=.29,95 \% \mathrm{CI}=[-0.09 \\
0.31]\end{array}$ \\
\hline$(\mathrm{N}=81)$ & $\begin{array}{c}\beta=00.40, \mathrm{SE}=0.11, \mathrm{t}(77)= \\
0.34, p<.001,95 \% \mathrm{CI}= \\
{[0.17,0.64]}\end{array}$ & $\begin{array}{c}\beta=0.64, \mathrm{SE}=0.13, \mathrm{t}(77)= \\
4.92, p<.001,95 \% \mathrm{CI}= \\
{[0.38,0.89]}\end{array}$ & $\begin{array}{c}\beta=0.11, \mathrm{SE}=0.08, \mathrm{t}(77)= \\
1.33, p=.18,95 \% \mathrm{CI}=[-0.05 \\
0.29]\end{array}$ \\
\hline $\begin{array}{l}\text { Study } 4 \\
(\mathrm{~N}=77)\end{array}$ & $\begin{array}{c}\beta=0.57, \mathrm{SE}=0.14, \mathrm{t}(73)= \\
3.84, p<.001,95 \% \mathrm{CI}= \\
{[0.27,0.86]}\end{array}$ & $\begin{array}{c}\beta=0.51, \mathrm{SE}=0.16, \mathrm{t}(73)= \\
3.18, p=.002,95 \% \mathrm{CI}= \\
{[0.19,0.83]}\end{array}$ & $\begin{array}{c}\beta=-0.05, \mathrm{SE}=0.21, \mathrm{t}(73)= \\
-0.27, p=.78,95 \% \mathrm{CI}= \\
{[-0.49,0.37]}\end{array}$ \\
\hline $\begin{array}{l}\text { Study } 5 \\
(\mathrm{~N}=381)\end{array}$ & $\begin{array}{c}\beta=0.73, \mathrm{SE}=0.07, \mathrm{t}(277)= \\
0.94, p<.001,95 \% \mathrm{CI}= \\
{[0.58,0.89]}\end{array}$ & $\begin{array}{c}\beta=0.78, \mathrm{SE}=0.06, \mathrm{t}(277)= \\
12.12, p<.001,95 \% \mathrm{CI}= \\
{[0.65,0.91]}\end{array}$ & $\begin{array}{c}\beta=0.04, \mathrm{SE}=0.10, \mathrm{t}(277)= \\
0.49, p=.62,95 \% \mathrm{CI}=[-0.14 \\
0.24]\end{array}$ \\
\hline
\end{tabular}

\footnotetext{
${ }^{3}$ The single-paper meta-analysis involved a sample of 15775 participants, a number larger than that needed to reject the null-hypothesis $(N=1193$; power $=.80)$ for an interaction associated with an effect of this size $\left(f^{2}=.00081\right)$.
} 


$\begin{array}{cccc}\text { Study } 6 & \beta=0.30, \mathrm{SE}=0.13, \mathrm{t}(113)= & \beta=0.63, \mathrm{SE}=0.13, \mathrm{t}(113)= & \beta=0.33, \mathrm{SE}=0.18, \mathrm{t}(113)= \\ & 2.30, p=.02,95 \% \mathrm{CI}= & 4.72, p<.001,95 \% \mathrm{CI}= & 1.76, p=.08,95 \% \mathrm{CI}=[-0.04, \\ (\mathrm{N}=117) & {[0.04,0.56]} & {[0.36,0.90]} & 0.70] \\ & & & \\ \text { Study } 7 & \beta=0.56, \mathrm{SE}=0.05, \mathrm{t}(331)= & \beta=0.53, \mathrm{SE}=0.06, \mathrm{t}(331)= & \beta=-0.03, \mathrm{SE}=0.08, \mathrm{t}(331)= \\ & 9.66, p<.001,95 \% \mathrm{CI}= & 8.04, p<.001,95 \% \mathrm{CI}= & -0.39, p=.69,95 \% \mathrm{CI}= \\ (\mathrm{N}=335) & {[0.45,0.68]} & {[0.40,0.66]} & {[-0.20,0.13]}\end{array}$

\section{Discussion}

Study 2 indicates that the conversationality of experiences and that of objects are similarly associated with happiness. Put simply, one unit of experience conversationality produces about as much happiness as does one unit of object conversationality. Adding to Study 1's evidence, this result supports the notion that experiential and material conversations are similarly beneficial for happiness.

\section{Study 3-Framed Purchase}

Study 3 employs a mental framing procedure to examine the replicability of Study 2 with a more controlled approach where the focal purchase is kept constant and participants' focus—on the experiential versus material aspects of the purchase — is experimentally manipulated (Bastos, 2019; Bastos and Brucks, 2017; Carter and Gilovich, 2012; Rosenzweig and Gilovich, 2012).

\section{Procedures}

One hundred and one Mturk participants completed the study in exchange for financial compensation $\left(64 \%\right.$ females; $\left.M_{\text {age }}=39.38, S D=12.29\right)$. The study randomly assigned participants to the experiential or material framing condition about a BBQ grill. To encourage the enrolment of actual BBQ owners, the study title informed that, "We are particularly interested in people who have a BBQ grill at home.” To manipulate the experiential versus material frame, participants were encouraged to think and describe their BBQ grill in terms of its experiential or material aspects. Following, participants answered the same five- and two-item measures of 
conversationality $(\alpha=.95)$ and happiness $(r=.58, p<.001)$. Next, they answered a two-item manipulation check measure (e.g., "The BBQ I described earlier is:" 1 = Definitely about a material object; $7=$ Definitely about an event or an activity; $r=.74, p<.001)$. Last, participants indicated whether they had a grill at their house (please see Web Appendix D for complete manipulation text and measurement items).

The framing manipulation had the intended effect, as experiential condition participants perceived the BBQ grill to be more experiential $(M=4.61, S D=1.80)$ than did material condition participants $(M=3.01, S D=2.06 ; t(98)=4.12, p<.001$, mean difference $=1.60,95 \%$ $\mathrm{CI}=[0.83,2.36]$, Cohen's $d=0.82$; see Table 4 for ANOVA results in tabular form).

Table 4

Manipulation Check of Framing Intervention (ANOVA)—Study 3

\begin{tabular}{lccccc}
\hline Factor & SS & df & MS & $F$ & $p$ \\
\hline Framing (experiential vs. & 64.00 & 1 & 64.00 & 17.02 & $<.001$ \\
material) & 368.39 & 98 & 3.75 & & \\
Error & & & & & \\
\hline
\end{tabular}

\section{Results}

One participant was excluded for indicating that she did not have a BBQ grill at the house, leaving a final sample of 100 participants. All results replicate when this excluded participant is included in the analyses.

Analysis of Moderation. Results showed that conversationality influences happiness in both the material $(\beta=0.21, S E=0.09, t(96)=4.44, p<.001,95 \% \mathrm{CI}=[0.22,0.59])$ and experiential framing conditions $(\beta=0.33, S E=0.11, t(96)=2.91, p=.004,95 \% \mathrm{CI}=[0.10$, 0.55]). Importantly, the magnitudes of these two effects are statistically indistinguishable $(\beta=$ $-0.08, S E=0.14, t(96)=-0.55, p=.58,95 \% \mathrm{CI}=[-0.37,0.20])$, supporting Hypothesis 1. 


\section{Discussion}

Study 3 replicates Studies 1 and 2 using a more controlled procedure where the focal purchase (a BBQ grill) is kept constant and the way people think of it (as an experience or an object) is experimentally manipulated. Consistent with the previous findings, results show that the conversationality of experiences and that of objects are similarly beneficial for happiness.

Studies 1-3 indicate that conversing about an object or an experience advance one's happiness by similar degrees. This knowledge has important implications for theory and practice. Specifically, together with the finding that experiential purchases advance more happiness than material purchases because they get talked about more frequently (Bastos and Brucks, 2017; Kumar and Gilovich, 2015), the findings from Studies 1-3 suggest that objects with high conversationality - those that generate much WOM-advance greater happiness, perhaps to a level similar to that advanced by experiences. For marketing managers, this idea suggests that, if firms providing objects intend to increase the happiness consumers gain from those purchasesperhaps to the level of experiential purchases'-, they should encourage more WOM conversations about those objects. Study 4 examines this possibility.

\section{Study 4-Manipulation of Purchase Conversationality}

This study examines the replicability of the previous findings and tests whether objects with higher conversationality increase consumer happiness more, possibly putting them at par with experiences in terms of ability to advance happiness. To do so, Study 4 uses a threecondition design: material purchases (serving as control condition), material purchases with high conversationality, and experiential purchases. In light of the previous findings, material purchases with high conversationality should advance significantly more consumer happiness 
than material purchases in general; a happiness increase that may reach the level of experiential purchases. Study 4 examines this possibility.

\section{Procedures}

Two hundred and one Mturk participants $\left(59 \%\right.$ females; $\left.M_{\text {age }}=32.98, S D=10.90\right)$ completed the study for financial compensation. Participants were randomly assigned to one of the three conditions: material $(N=67)$, material with high conversationality $(N=69)$, or experiential condition $(N=65)$. Using manipulation scripts similar to Study 2's, this study asked participants in the two material conditions (vs. those in the one experiential condition) to recall and write about an object (vs. experience) they had purchased in the last 12 months for about \$50. To manipulate high conversationality in the material with high conversationality condition, the study showed participants in that condition (but not those in the material or experiential conditions) the additional information: "Important: This is an object that makes for a good conversation. You have talked about it with other people and it is a good topic to talk about."

Following the writing task, participants answered the same two-item measure of happiness $(r=.65, p<.001)$, five-item measure of purchase conversationality (serving as manipulation check; $\alpha=.96$ ), and three-item manipulation check measure of purchase type used in Study $2(\alpha=.86)$.

The two manipulation checks (for purchase type and purchase conversationality) confirmed the success of the manipulations. First, an ANOVA with condition (material vs. material with conversationality vs. experiential) as the independent variable and the manipulation check of purchase type as the dependent variable showed a significant overall effect $(F(1,198)=$ 149.35, $p<.001)$. As expected, participants in the experiential condition perceived the purchase as more experiential $(M=5.70, S D=1.59)$ than did participants in the material $(M=1.80, S D=$ 
$1.15, p<.001$, mean difference $=3.89,95 \% \mathrm{CI}=[3.41,4.38]$, Cohen's $d=2.81)$ and those in the material with high conversationality conditions $(M=2.27, S D=1.46, p<.001$, mean difference $=3.43,95 \% \mathrm{CI}=[2.95,3.91]$, Cohen's $d=2.24)$. The latter two conditions were statistically indistinguishable, although the difference approached the conventional criterion for statistical significance $(p=.057$, mean difference $=0.46,95 \% \mathrm{CI}=[-0.01,0.94]$, Cohen's $d=0.35$; see Table 5 for ANOVA results in tabular form). These results confirm that participants listed purchases in line with the purchase type condition they had been assigned.

Table 5

Manipulation Check of Condition (ANOVA)—Study 4

\begin{tabular}{|c|c|c|c|c|c|}
\hline Factor & SS & $\mathrm{df}$ & MS & $F$ & $p$ \\
\hline $\begin{array}{l}\text { Condition: material vs. } \\
\text { material with high } \\
\text { conversationality vs. } \\
\text { experiential } \\
\text { Error }\end{array}$ & $\begin{array}{l}597.62 \\
396.12\end{array}$ & $\begin{array}{c}2 \\
198\end{array}$ & $\begin{array}{c}298.81 \\
2.00\end{array}$ & 149.35 & $<.001$ \\
\hline
\end{tabular}

Second, an ANOVA with condition predicting purchase conversationality showed a significant overall effect $(F(1,198)=10.81, p<.001)$. As in Studies 2 and 3, participants in the experiential purchase condition perceived the purchase to have greater conversationality ( $M=$ $5.25, S D=1.56)$ than did participants in the material purchase condition $(M=4.44, S D=1.63, p$ $=.001$, mean difference $=0.81,95 \% \mathrm{CI}=[0.32,1.30]$, Cohen's $d=0.50)$. As intended by the conversationality manipulation, participants in the material with high conversationality condition reported greater conversationality $(M=5.54, S D=1.01)$ than did those in the material condition $(p<.001$, mean difference $=1.10,95 \% \mathrm{CI}=[0.61,1.58]$, Cohen's $d=0.81)$; however there was no difference between participants in the material with conversationality and those in the experiential conditions $(p=.24$, mean difference $=0.29,95 \% \mathrm{CI}=[-0.19,0.77]$, Cohen's $d=$ 
0.22; see Table 6 for ANOVA results in tabular form). These results confirm the success of the conversationality manipulation and indicate an equivalence on that dimension between material with high conversationality and experiential condition participants (please see Figure 2).

Table 6

Manipulation Check of Conversationality (ANOVA)-Study 4

\begin{tabular}{|c|c|c|c|c|c|}
\hline Factor & SS & df & MS & $F$ & $p$ \\
\hline $\begin{array}{l}\text { Condition: material vs. } \\
\text { material with high } \\
\text { conversationality vs. } \\
\text { experiential }\end{array}$ & 43.94 & 2 & 21.97 & 10.81 & $<.001$ \\
\hline Error & 402.31 & 198 & 2.03 & & \\
\hline
\end{tabular}

Figure 2. Manipulation check for purchase conversationality

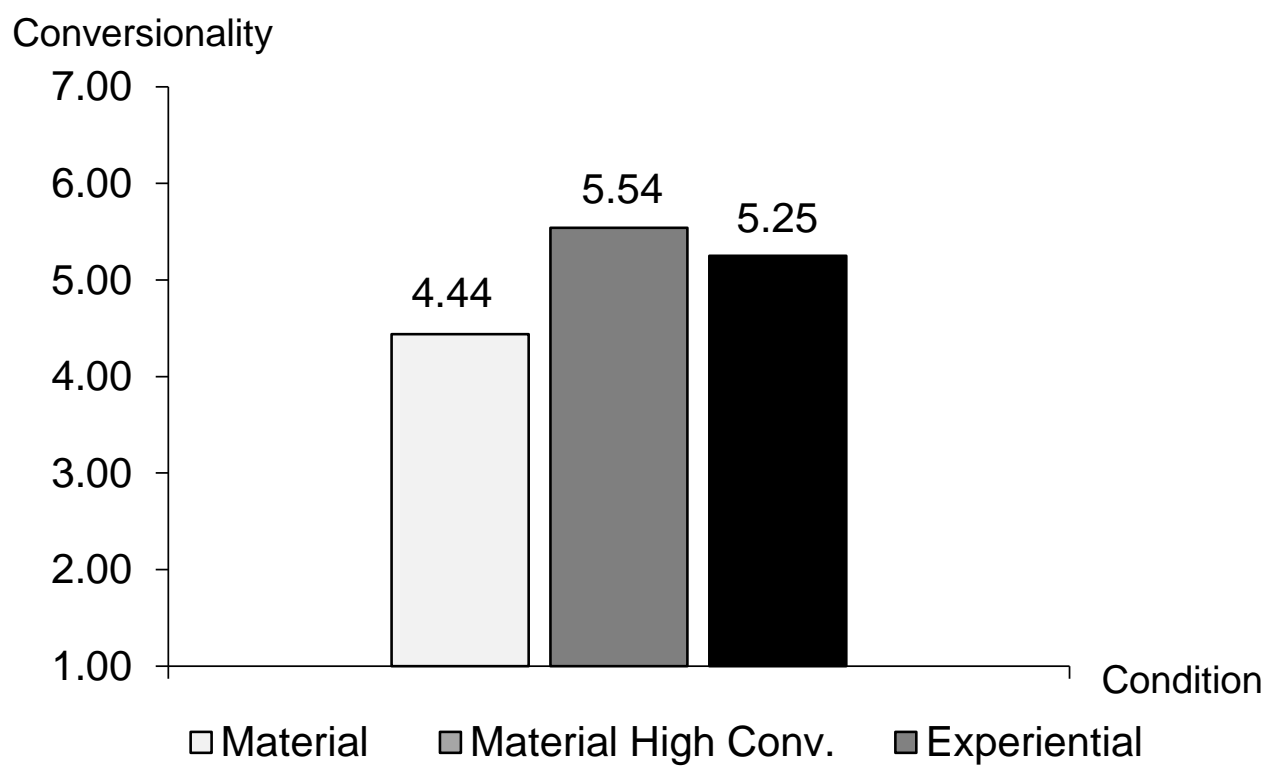

In light of these results, the next analysis examines whether the observed patterns in conversationality have the expected downstream effect on happiness, such that the material with 
high conversationality and the experiential conditions yield significantly greater values than does the material condition, but are statistically indistinguishable from each other.

\section{Results}

Results indicated an overall effect of condition on happiness $(F(1,198)=8.15, p<.001)$. As expected, participants in the material with high conversationality condition $(M=5.60, S D=$ $1.02, p=.003$, mean difference $=0.61,95 \% \mathrm{CI}=[0.21,1.01]$, Cohen's $d=0.53)$ and those in the experiential conditions $(M=5.77, S D=1.21, p<.001$, mean difference $=0.79,95 \% \mathrm{CI}=[0.38$, 1.20], Cohen's $d=0.62$ ) each reported gaining significantly more happiness from the purchase than did participants in the material condition $(M=4.98, S D=1.30)$; and the first two conditions were statistically indistinguishable on happiness $(p=.39$, mean difference $=0.17,95 \% \mathrm{CI}=$ $[-0.22,0.58]$, Cohen's $d=0.15$; please see Table 7 for ANOVA results in tabular form and Figure 3 for a graphical depiction of the results).

Table 7

Effect of Condition on Happiness (ANOVA)—Study 4

\begin{tabular}{lccccc}
\hline Factor & SS & df & MS & $F$ & $p$ \\
\hline $\begin{array}{l}\text { Condition: material vs. } \\
\text { material with high } \\
\begin{array}{l}\text { conversationality vs. } \\
\text { experiential }\end{array}\end{array}$ & & & & & \\
\begin{tabular}{l} 
Error \\
\hline
\end{tabular} & 23.01 & 2 & 11.50 & 8.15 & $<.001$ \\
& 279.29 & 198 & 1.41 & & \\
\hline
\end{tabular}


Figure 3. The effect of condition on happiness

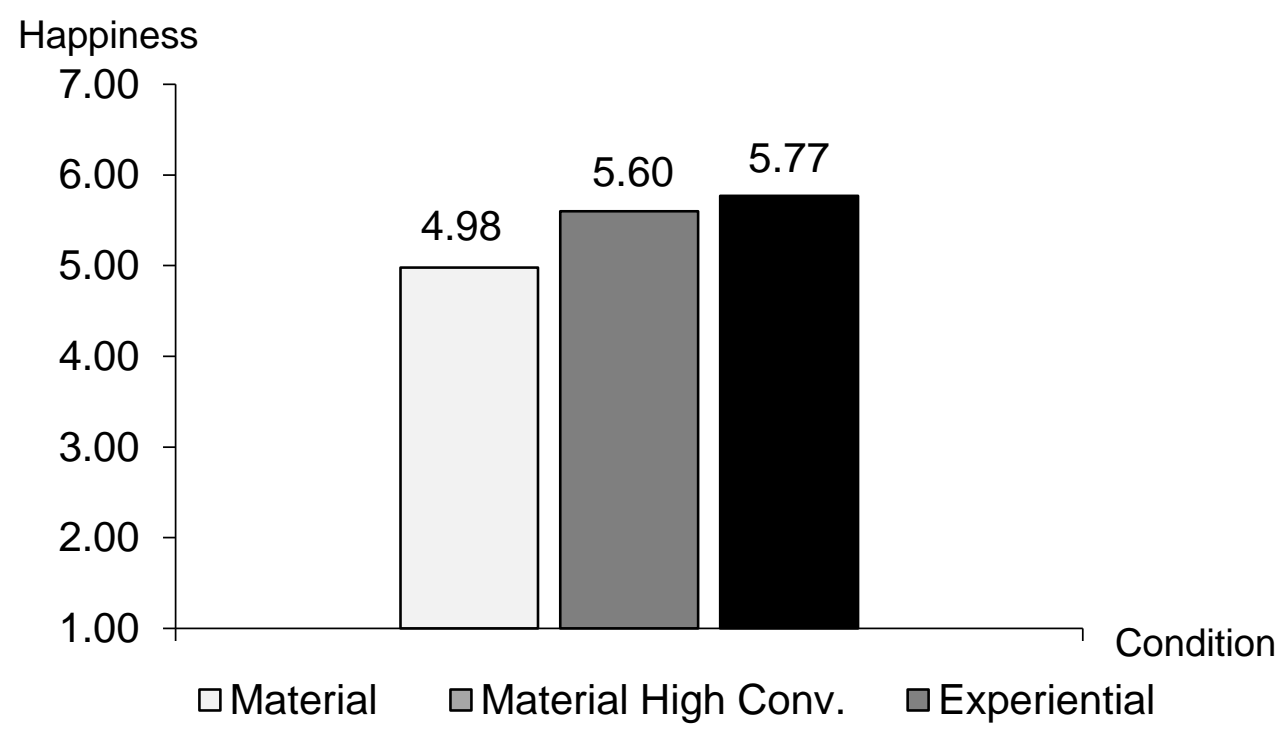

\section{Discussion}

Study 4 demonstrates that objects with higher conversationality offer consumers greater happiness. Importantly, these objects provide levels of happiness equivalent to those normally provided by experiences. This result shows that purchase conversationality is a productive way of increasing the objects' ability to advance consumer happiness.

It is theoretically and managerially useful to know that the ability to advance consumer happiness is not exclusive to experiences. Also, by manipulating purchase conversationality, Study 4 adds to Study 1's evidence of causal directionality. By its own nature, this strategy neutralizes the alternative causal pathway because differences in purchase conversationality cannot be attributed to happiness, whereas differences in happiness can be attributed to the manipulated level of purchase conversationality (Spencer et al., 2005).

\section{General Discussion}

This paper documents evidence from four studies that conversing about an object or an experience are equally beneficial for consumer happiness. This conclusion contributes to theory 
in four major ways: It deepens the understanding of how the purchase conversationality model unfolds, clarifies previous claims made in the literature, shows a new boundary condition for the happiness superiority of experiences, and establishes the causal direction of the effect:

conversationality $\rightarrow$ happiness. These contributions are discussed further next.

\section{Theoretical Contributions}

Drawing on past research, this work theorizes for two competing hypotheses. It then uses novel approaches to disentangle conversation frequency (the left side of the model displayed on Figure 1) from each conversation's ability to advance happiness (the right side of the model). The convergent findings offer a deeper comprehension of where, precisely, the conversationality effect happens: The mediating effect of conversationality appears to reside on the left side of the model only — the 'purchase type $\rightarrow$ purchase conversationality' link; and not on the right side of the model — a purchase type moderation of the 'purchase conversationality $\rightarrow$ happiness' link (see Figure 4). In other words, an experiential purchase tends to generate more conversations than does a material purchase, as shown by previous research (Bastos and Brucks, 2017; Kumar and Gilovich, 2015) and replicated here, but the evidence from Studies 1-3 and the supplemental materials (Web Appendices E) all indicate that each conversation about an object or an experience advances about the same level of happiness.

This finding qualifies the previously found effect of purchase conversationality as one associated with frequency, only. That is, sharing explains the happiness superiority of experiences over objects because consumers tend to talk more often about the former than the latter. However, that is a matter of frequency, and not of each conversation's ability to generate happiness, as talking about experiences or objects leads to in similar advancements in happiness. 
This result suggests that lay theories about the stronger effect of experiential (vs. material) conversations on happiness (Kumar and Gilovich, 2015) are misaligned with empirical evidence; a possibility that gains traction in studies involving hypothetical and future-based approaches where participants' reporting is largely inferential. Using empirical evidence, the present investigation therefore clarifies previous claims made in the literature.

Figure 4. Purchase Conversationality Model—A Deeper Understanding

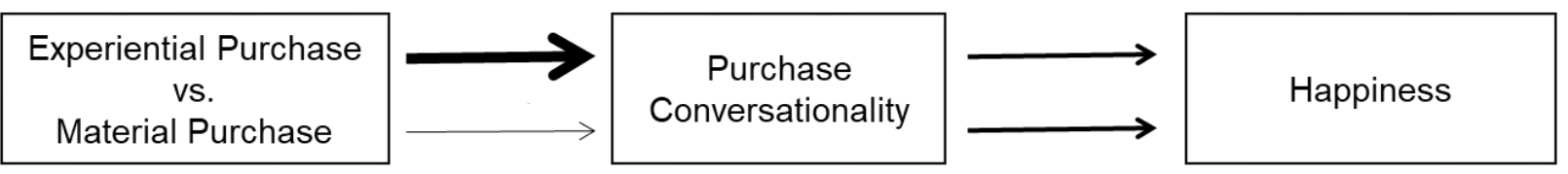

This more complete understanding of the purchase conversationality effect suggests an interesting possibility: That increasing the conversationality of an object, such that consumers share about it as much as they normally share about experiences, may enable that object to advance high levels of happiness similar to those normally advanced by experiences. Study 4 tests and finds evidence supporting this notion. This finding adds to the literature a new boundary condition of the happiness superiority of experiences. Previous research on the boundaries of the experiential superiority documented that experiences cultivate more happiness than objects because people are more likely to consume them socially (vs. solo); but that, when both purchase types are consumed in the presence of others, they generate equivalent amounts of happiness (Caprariello and Reis, 2013). Likewise, consumers are relatively more enthusiastic about telling others about their experiences than their objects (Bastos and Brucks, 2017; Kumar and Gilovich, 2015), but the evidence presented here indicates that when they talk more about their objects, such that this dimension reaches the level normally seen for experiences, the two purchase types generate equivalent levels of consumer happiness. 
The present work therefore enhances the understanding of how people benefit psychologically from a different type of social interaction centered on a purchase. Of note, the present work differs from most of the previous research in one important way: Whereas that research focuses predominantly on interactions that occur during the experience-e.g., interactions among individuals partaking in religious and musical events (Hills and Argyle, 1998), museum visits (Ratner and Hamilton, 2015), movie watching (Ramanathan and McGill, 2007), and food consumption (Ragunathan and Corfman, 2006) - , the current work explores a kind of interaction that transcends the moment of consumption - -i.e., WOM conversation —and demonstrates that it too increases consumer happiness.

Finally, by manipulating conversation topic (Study 1) and purchase conversationality (Study 4) this investigation conclusively establishes the direction of the causal effect: from conversationality to happiness. Previous research in this domain heavily relied on regressionbased mediation analysis (Bastos and Brucks, 2017; Kumar and Gilovich, 2015) and therefore left open the possibility of inverse causality: That experiences are more conversational than objects because they make people happier. This possible inverse effect is consistent with the notion that, in regression-based analysis, "the path between mediator and outcome is a (partial) correlation. It does not imply causation" (Pieters, 2017, p. 694). Determining the causal directionality is an important addition to the literature because it allows for more refined theorization and improved decision-making by managers.

\section{Practical Implications for Managers and Consumers}

Firms have invested substantial resources to encourage consumers to talk. For example, to foster WOM, Coca-Cola placed the names of regular individuals on its label (the Share a Coke campaign), and Milka created a whole new production system able to remove one square from its 
multi-square chocolate bar (the Last Square campaign). These initiatives are worthwhile because they can bring various benefits to the firm (Berger, 2014; Sweeney et al., 2014) and, as this investigation shows, to the consumer as well - which can be interpreted as an indirect benefit to the firm. Naturally, WOM campaigns are more likely to succeed when resources are optimally allocated, thus marketing managers can benefit from knowledge about where their WOM efforts are more likely to pay dividends. The findings presented here indicate that spending resources to increase the frequency of WOM about either purchase type (material or experiential purchases) will likely engender equivalent advancements in consumer happiness. However, the manager is wise to recognize that, since consumers already tend to share more about their experiences (vs. objects; Bastos and Brucks, 2017), there is more room for growth in the frequency of material (vs. experiential) conversations. But how can marketing managers encourage consumers to share more about their objects?

Study 3, centered on a material purchase (a BBQ grill), offers evidence that a mental framing intervention is a useful tool for managers to increase the conversationality of objects. BMW's \#Un4gettable Weekend campaign, where BMW fans engaged in weekend-long activities involving the brand's automobiles, exemplifies how managers can highlight the experiential aspects of a predominantly material product to motivate WOM. Indeed, this campaign generated 2.8 million impressions on twitter alone (Alini, 2014); and based on this investigation's findings, it likely also advanced the happiness those consumers derive from the product.

It is worth noting that this knowledge is particularly timely. Whereas a substantial portion of the world's economy revolves around material objects (OECD, 2018), this purchase type has been losing its appeal among a critical consumer sector-millennials in the developed world. These young consumers are increasingly turning away from spending on material things in favor 
of having life experiences (Morgan, 2015), a trend that has been referred to as the "experience economy" (Usborne, 2017). Experiences, they perceive, is key to their transition into adulthood (Weinberger et al., 2017), making unique experiences particularly valuable to them (Bhattacharjee and Mogilner, 2013). The knowledge presented here points to purchase conversationality as a tool managers can use to increase the happiness consumers gain from their objects, which could help material purchases regain some of their appeal.

Finally, Study 1 provides two additional pieces of information relevant to the marketing manager. First, the pre-test showed that conversations about an object or an experience lasted similar amounts of time; suggesting that consumers have as much to say about their objects as they do about their experiences, and that WOM efforts designed to equip material consumers with more conversational content may be unnecessary. Second, even when consumers share with a complete stranger (as Study 1's participants did) their happiness tends to benefit. This finding dovetails with previous evidence that, although train and bus commuters expect to enjoy the ride less if they converse with a stranger, those who do engage in a conversation with an unknown rider report a happier ride than those who do not (Epley and Schroeder, 2014). This is encouraging for managers and consumers alike since most of people's conversations in fact do not occur with strangers but with known others (Gable et al., 2006).

As a central figure in this research, the consumer is a main beneficiary of the knowledge advanced here. People have a strong desire to socially interact (e.g., Baumeister and Leary, 1995) and interpersonal conversations feature as a highly meaningful form of interaction (Csikszentmihalyi and Larson, 1987). However, as the present work indicates, it appears that consumers have been missing out on valuable opportunities to converse more frequently about their objects and consequently increase their own happiness-i.e., consumers could be happier. 
Past evidence indicates that consumers' preference for sharing about experiences (vs. objects) stems from their belief that conversations about experiences are more conducive to social relationship development (Bastos and Brucks, 2017). Even if consumers' intuition is right (and there is evidence suggesting that they likely are [Van Boven et al., 2010; Study 5]), the finding that material conversations are just as capable of advancing happiness suggests that those conversations make up for this social deficiency in other ways. For example, sharing is often a way of gaining "support and justification for a purchase decision" (Gatignon and Robertson, 1986, p. 534). Although people tend to mentally form different impressions about individuals associated with objects versus experiences (Van Boven et al., 2010), social norms governing conversation (Christophe and Rimé, 1997) may motivate them to display approval of both purchase types - e.g., by complimenting the purchase (Chan and Sengupta, 2013). This social support for the purchase might thus attenuate the feeling of regret predominantly associated with making material (vs. experiential) purchases (Rosenzweig and Gilovich, 2012). Further, sharing may interrupt or delay the process of adaptation whereby objects lose their appeal faster than experiences (Nicolao et al., 2009). Talking about a purchase brings the (otherwise fading) positive aspects of the purchase to the forefront of one's attention (Gable et al., 2004; Langston, 1994), perhaps neutralizing (at least momentarily) the differential in duration of the purchase's positive effects (Verduyn et al., 2011). These ideas are fruitful avenues for future research looking at ways to increase consumers' happiness with objects.

\section{Limitations and Future Research}

The present work opens several avenues for future inquiries. Researchers interested in the positive aspects of conversations about objects could consider factors such as easiness of thinking of something to share (Bastos and Brucks, 2017). Also, due to their inherent 
permanence (Tully et al., 2015), material items are particularly apt for transporting people back to the emotions experienced during a special moment (Goodman et al., 2016). Sharing about those material objects might thus provide a memory benefit above and beyond that of owning them (Zauberman et al., 2009). Here, unique objects (Rosenzweig and Gilovich, 2012) feature as a particularly promising area for exploration.

A note of caution is that, although the conspicuous consumption or verbal sharing of both objects and experiences can engender unfavorable judgments (Fournier and Richins, 1991), objects still appear more prone than experiences to elicit negative reactions (Van Boven et al., 2010). Hence, consumers are well-advised to exert caution in selecting their conversation partners when the interaction will center on material topics (Chen, 2017). Further, it is possible (albeit only speculatively here) that these object-based conversations are particularly beneficial when the conversation partners share an interest in the object (as when coin collectors interact), the conversation has an altruistic instead of a self-enhancement tone (as when the teller recommends something useful to the conversation partner), or the conversation leads to selfdisclosure (as when the teller shares about a self-made object that reflects her identity). Future research could consider these possibilities.

In addition, future investigations could examine the possibility that conversing about an object is beneficial because it changes the very way the owner perceives it, such that, psychologically, the object becomes more like an experience. Researchers have argued (but not tested) that, compared with objects, experiences are a more suitable topic of conversation because they "are more likely to have a typical narrative structure with a beginning, middle, and end" (Van Boven and Gilovich, 2003, p. 1200). Although this is an interesting and intuitively appealing idea, it is also possible that when consumers share about their objects, the content of 
the conversation shows a similar story-like structure to that of experiences, thus imbuing the object with a positive aspect normally associated with experiences - a narrative structure. Such conversation could include, for example, the purchasing process (beginning), the instances when the owner used the object (middle), and how s/he evaluates it afterwards (end). Alternatively, when the conversation focuses on the object itself, the teller may be motivated to talk more about its uses than on its physical properties as a way to avoid potential materialism stigmas.

Further, it could be interesting to examine moderators of the effects found here. For example, Tully et al. (2015) find that financially constrained consumers tend to value a purchase's longevity, which leads them to prefer investing in material over experiential purchases. Is it possible that financially constrained consumers prefer not only to acquire (Tully et al., 2015) but also to converse about material instead of experiential purchases? If so, the results of the present research suggest that this group of consumers would likely gain more happiness from objects than experiences (as a result of sharing more about them). Interestingly, in this case happiness would join longevity as potential explanations for these consumers' preference for objects; providing an even more complete understanding of Tully et al.'s model.

Finally, the present work joins a set of WOM investigations examining different categorizations of purchases (e.g., mainstream vs. non-mainstream products [Yang et al., 2012]; credence vs. experience services [Koo, 2015]). To extend knowledge in this research domain, future works could to delve deeper into these categories in search for idiosyncrasies that may point to additional moderators.

The present investigation has several limitations, some of which point to additional avenues for future inquiries. Notably, this work theorizes for two competing hypotheses and avoids HARKing, thus welcoming any type of result, including non-significant ones (i.e., it 
provides transparency). Indeed, the main conclusion from this research rests, in part, on nonsignificant interaction effects (which are reinforced and summarized in the single-paper metaanalysis). However, non-significant interaction effects can result from reasons other than simple effects that truly are statistically indistinguishable-e.g., insufficient power, and poor manipulation interventions and measurement (Sawyer and Peter, 1983). To rule out these possibilities, this research used appropriate statistical power to detect a potential significant interaction effect (please see footnote 2), adopted commonly-used experimental procedures and employed manipulation checks to confirm the success of the manipulation interventions (Studies 2-4), and used established measures of purchase conversationality and consumer happiness, which performed satisfactorily across the current studies.

Further, to increase confidence in the findings, this work documents seven additional studies serving as replications (see Table 1 for a summary and Web Appendix E for detailed descriptions of each replication). Additionally, the control condition in Study 1 provides a reliable baseline against which to show the similar increases in happiness for experiential and material conversations. To the author's knowledge, Study 1 is the first in this research domain to engage participants in an actual conversation with another person, assess their happiness both before and after the conversation interaction, and employ a control condition; which are arguably the optimal procedures to examine the research question presented here. Future work could adopt this procedure to identify the boundaries of the effects reported here.

Whichever direction future research in this domain takes, the author trusts that the present findings will seed additional work in the areas of WOM conversations and happiness, with beneficial implications for theory and society. 


\section{References}

Ahrens, J., Coyle, J. R., and Strahilevitz, M. A. (2013), "Electronic word of mouth: The effects of incentives on e-referrals by senders and receivers", European Journal of Marketing, Vol. 47 No. 7, pp. 1034-1051.

Alini, K. (2014), BMW: Ultimate fan engagement, Vimeo, https://vimeo.com/91106967.

Altman, I., and Taylor, D. (1973), Social penetration theory, Holt Rinehart \& Minston, New York.

Anderson, E. W., Fornell, C., and Lehmann, D. R. (1994), “Customer satisfaction, market share, and profitability: Findings from Sweden", The Journal of Marketing, Vol. 58 No. 3, pp. $53-66$.

Babie Rosario, A., Sotgiu, F., de Valck, K., and Bijmolt, Tammo H.A. (2016), "The effect of electronic word of mouth on sales: A meta-analytic review of platform, product, and metric factors", Journal of Marketing Research, Vol. 53, pp. 297-318.

Bandura, A. (1977), Social learning theory, Prentice Hall, New Jersey.

Bastos, W., (2019, forthcoming), "Now or never: Perceptions of uniqueness induce acceptance of price increases for experiences more than for objects", Journal of Consumer Psychology. doi:10.1002/jcpy.1099

Bastos, W., and Brucks, M. (2017), "How and why conversational value leads to happiness for experiential and material purchases", Journal of Consumer Research, Vol. 44, pp. 598612.

Baumeister, R. F., and Leary, M. R. (1995), “The need to belong: Desire for interpersonal attachments as a fundamental human motivation”, Psychological Bulletin, Vol. 117 No. 3, pp. 497-529. 
Berger, J. (2014), "Word of mouth and interpersonal communication: A review and directions for future research", Journal of Consumer Psychology, Vol. 24 No. 4, pp. 586-607.

Berger, J., and Schwartz, E. M. (2011), "What drives immediate and ongoing word of mouth?", Journal of Marketing Research, Vol. 48 No. 5, pp. 869-880.

Bhattacharjee, A., and Mogilner, C. (2013), "Happiness from ordinary and extraordinary experiences", Journal of Consumer Research, Vol. 41 No. 1, pp. 1-17.

Caprariello, P. A., and Reis, H. T. (2013), “To do, to have, or to share? Valuing experiences over material possessions depends on the involvement of others", Journal of Personality and Social Psychology, Vol. 104 No. 2, pp. 199-215.

Carter, T. J., and Gilovich, T. (2010), "The relative relativity of material and experiential purchases", Journal of Personality and Social Psychology, Vol. 98 No. 1, pp. 146-159.

Carter, T. J., and Gilovich, T. (2012), "I am what I do, not what I have: The differential centrality of experiential and material purchases to the self", Journal of Personality and Social Psychology, Vol. 102 No. 6, pp. 1304-1317.

Chan, E., and Sengupta, J. (2013), "Observing flattery: A social comparison perspective", Journal of Consumer Research, Vol. 40 No. 4, pp. 740-758.

Chen, Z. (2017), "Social acceptance and word of mouth: How the motive to belong leads to divergent WOM with strangers and friends", Journal of Consumer Research, Vol. 44 No. 3, pp. 613-632.

Christophe, V., and Rimé, B. (1997), "Exposure to the social sharing of emotion: Emotional impact, listener responses and secondary social sharing." European Journal of Social Psychology, Vol. 27 No. 1, pp. 37-54. 
Collins, N. L., and Miller, L. C. (1994), "Self-disclosure and liking: A meta-analytic review. Psychological Bulletin", Vol. 116 No. 3, pp. 457-475.

Consiglio, I., De Angelis, M., and Costabile, M. (2018), “The effect of social density on word of mouth", Journal of Consumer Research, Vol. 45 No. 3, 511-528.

Cooney, G., Gilbert, D. T., and Wilson, T. D. (2017), “The novelty penalty: Why do people like talking about new experiences but hearing about old ones?", Psychological Science, Vol. 28 No. 3, pp. 380-394.

Crano, W., Brewer, M., and Lac, A. (2014), Principles and methods of social research, Routledge, New York.

Csikszentmihalyi, M., and Larson, R. (1987), "Validity and reliability of experience sampling method", Journal of Nervous and Mental Diseases, Vol. 175 No. 9, pp. 526-536.

Epley, N., and Schroeder, J. (2014), “Mistakenly seeking solitude”, Journal of Experimental Psychology: General, Vol. 143 No. 5, pp. 1980-1999.

Escalas, J. E. (2006), "Self-referencing and persuasion: Narrative transportation versus analytical elaboration”, Journal of Consumer Research, Vol. 33 No. 4, pp. 421-429.

Filo, K., Lock, D., and Karg, A. (2015), “Sport and social media research: A review”, Sport Management Review, Vol. 18 No. 2, 166-181.

Fournier, S., and Richins, M. (1991), "Some theoretical and popular notions concerning materialism", Journal of Social Behavior and Personality, Vol. 6 No. 6, pp. 403-414.

Gable, S. L., Gonzaga, G., and Strachman, A. (2006), "Will you be there for me when things go right? Supportive responses to positive event disclosures", Journal of Personality and Social Psychology, Vol. 91 No. 5, pp. 904-917. 
Gable, S. L., Reis, H. T., Impett, E. A., and Asher, E. R. (2004), "What do you do when things go right? The intrapersonal and interpersonal benefits of sharing positive events", Journal of Personality and Social Psychology, Vol. 87 No. 2, pp. 228-245.

Gatignon, H., and Robertson, T. S. (1986), An exchange theory model of interpersonal communication. Advances in Consumer Research, Vol. 13, ed. Richard J. Lutz, Provo, UT: Association for Consumer Research, pp. 534-538.

Gelper, S., Peres, R., and Eliashberg, J. (2018), “Talk bursts: The role of spikes in prerelease word-of-mouth dynamics", Journal of Marketing Research, Vol. 55 No. 6, 801-817.

Goodman, J. K., Malkoc, S. A., and Stephenson, B. L. (2016), “Celebrate or commemorate? A material purchase advantage when honoring special life events", Journal of the Association for Consumer Research, Vol. 1 No. 4, pp. 497-508.

Huang, J. H., and Chen, Y. F. (2006), "Herding in online product choice", Psychology and Marketing, Vol. 23 No. 5, pp. 413-428.

Jones, M. A., Taylor, V. A., and Reynolds, K. E. (2014), “The effect of requests for positive evaluations on customer satisfaction ratings," Psychology \& Marketing, Vol. 31 No. 3, pp. $161-170$.

Kerr, N. L. (1998), "HARKing: Hypothesizing after the results are known", Personality and Social Psychology Review, Vol. 2 No. 3, pp. 196-217.

Koo, D-M. (2015), “The strength of no tie relationship in an online recommendation: Focused on interactional effects of valence, tie strength, and type of service", European Journal of Marketing, Vol. 49 No. 7/8, pp. 1163-1183. 
Krishna, A. (2012), “An integrative review of sensory marketing: Engaging the senses to affect perception, judgment and behavior”, Journal of Consumer Psychology, Vol. 22 No. 3, pp. $332-351$.

Kumar, A., and Gilovich, T. (2015), "Some "thing” to talk about? Differential story utility from experiential and material purchases", Personality and Social Psychology Bulletin, Vol. 41 No. 10, pp. 1320-1331.

Langston, C. A. (1994), “Capitalizing on and coping with daily-life events: Expressive responses to positive events", Journal of Personality and Social Psychology, Vol. 67, pp. 11121125.

Lyubomirsky, S., King, L., and Diener, E. (2005), “The benefits of frequent positive affect: Does happiness lead to success?”, Psychological Bulletin, Vol. 131 No. 6, pp. 803-855.

Mangold, W., and Faulds, D. J. (2009), "Social media: The new hybrid element of the promotion mix", Business Horizons, Vol. 52 No. 4, pp. 357-365.

Mehl, M. R., Vazire, S., Holleran, S.E., and Clark, C. S. (2010), “Eavesdropping on happiness: Well-being is related to having less small talk and more substantive conversations", Psychological Science, Vol. 21 No. 4, pp. 539-541.

Mitchell, T. R., Thompson, L., Peterson, E., \& Cronk, R. (1997), “Temporal adjustments in the evaluation of events: The "rosy view", Journal of Experimental Social Psychology, Vol. 33 No. 4, pp. 421-448.

Morgan, B. (2015), NOwnership, no Problem: Why millennials value experiences over owning things, Forbes, https://www.forbes.com/sites/blakemorgan/2015/06/01/ nownershipnoproblem-nowners-millennials-value-experiences-over-ownership/ 
Nicolao, L., Irwin, J. R., and Goodman, J. K. (2009), “Happiness for sale: Do experiential purchases make consumers happier than material purchases?", Journal of Consumer Research, Vol. 36 No. 2, pp. 188-198.

OECD (2018), Trade in goods (indicator). doi: 10.1787/1ea6b5ed-en (Accessed on 26 October 2018).

Opree, S.J., Buijzen, M., and van Reijmersdal, E.A. (2016), "The impact of advertising on children's psychological wellbeing and life satisfaction" European Journal of Marketing, Vol. 50 No. 11, pp. 1975-1992.

Packard, G., and Berger, J. (2017), “How language shapes word of mouth's impact”, Journal of Marketing Research, Vol. 54 No. 4, 572-588.

Pieters, R. (2017), “Meaningful mediation analysis: Plausible causal inference and informative communication", Journal of Consumer Research, Vol. 44 No. 3, pp. 692-716.

Popper, K. (1959), The logic of scientific discovery, Hutchinson \& Co.

Ragunathan, R., and Corfman, K. (2006), "Is happiness shared doubled and sadness shared halved? Social influence on enjoyment of hedonic experiences", Journal of Marketing Research, Vol. 43 No. 3, pp. 386-394.

Ramanathan, S., and McGill, A. L. (2007), “Consuming with others: Social influences on moment-to-moment and retrospective evaluations of an experience", Journal of Consumer Research, Vol. 34 No. 4, pp. 506-524.

Ratner, R. K., and Hamilton, R. W. (2015), “Inhibited from bowling alone”, Journal of Consumer Research, Vol. 42 No. 2, pp. 266-283. 
Romaniuk, J., and Hartnett, N. (2017), “The relative influence of advertising and word-of-mouth on viewing new season television programmes", European Journal of Marketing, Vol. 51 No. $1,65-81$.

Rosenthal, R. (1979), “The file drawer problem and tolerance for null results”, Psychological Bulletin, Vol. 86 No. 3, pp. 638-641.

Rosenzweig, E., and Gilovich, T. (2012), "Buyer's remorse or missed opportunity? Differential regrets for material and experiential purchases", Journal of Personality and Social Psychology, Vol. 102 No. 2, pp. 215-223.

Roy, G., Datta, B., and Mukherjee, S. (2019). "Role of electronic word-of-mouth content and valence in influencing online purchase behavior", Journal of Marketing Communications, Vol. 25 No. 6, 661-684.

Rubin, M. (2017), "When does HARKing hurt? Identifying when different types of undisclosed post hoc hypothesizing harm scientific progress", Review of General Psychology, Vol. 21 No. 4, pp. 308-320.

Sawyer, A. G., and Peter, J. P. (1983), “The significance of statistical significance tests in marketing research", Journal of Marketing Research, Vol. 20 No. 2, pp. 122-133.

Spencer, S., Zanna, M., and Fong, G. (2005), "Establishing a causal chain: Why experiments are often more effective than mediational analyses in examining psychological processes", Journal of Personality and Social Psychology, Vol. 89 No. 6, pp. 845-851.

Sweeney, J., Soutar, G., and Mazzarol, T. (2012), "Word of mouth: Measuring the power of individual messages”, European Journal of Marketing, Vol. 46 No. 1/2, pp. 237-257. 
Sweeney, J., Soutar. G., and Mazzarol, T. (2014), "Factors enhancing word-of-mouth influence: Positive and negative service-related messages", European Journal of Marketing, Vol. 48 No. 1/2, pp. 336-359.

Tully, S. M., Hershfield, H. E., and Meyvis, T. (2015), "Seeking lasting enjoyment with limited money: Financial constraints increase preference for material goods over experiences”, Journal of Consumer Research, Vol. 42 No. 1, pp. 59-75.

Usborne, S. (2017), Just do it: the experience economy and how we turned our backs on 'stuff', The Guardian, https://www.theguardian.com/business/2017/may/13/just-do-it-theexperience-economy-and-how-we-turned-our-backs-on-stuff

Van Boven, L., Campbell, M. C., and Gilovich, T. (2010), “Stigmatizing materialism: On stereotypes and impressions of materialistic and experiential pursuits", Personality and Social Psychology Bulletin, Vol. 36 No. 4, pp. 551-563.

Van Boven, L., and Gilovich, T. (2003), “To do or to have? That is the question”, Journal of Personality and Social Psychology, Vol. 85 No. 6, pp. 1193-1202.

Verduyn, P., Mechelen, I. V., and Tuerlinckx, F. (2011), “The relation between event processing and the duration of emotional experience", Emotion, Vol. 11 No. 1, pp. 20-28.

Weinberger, M., Zavisca, J., and Silva, J. (2017), “Consuming for an imagined future: Middle class consumer lifestyle and exploratory experiences in the transition to adulthood", Journal of Consumer Research, Vol. 44 No. 2, pp. 332-360.

Wilson, E., and Sherrell D. (1993), "Source effects in communication and persuasion research: A meta-analysis of effect size", Journal of the Academy of Marketing Science, Vol. 21 No. 2, pp.101-112. 
Yang, J., Kim, W., Amblee, N., and Jeong, J. (2012), “The heterogeneous effect of WOM on product sales: Why the effect of WOM valence is mixed?", European Journal of Marketing, Vol. 46 No. 11/12, pp. 1523-1538.

Yang Zhong, J., and Mitchell V-W. (2013), "When having is not enough: Implications of being satisfied”, European Journal of Marketing, Vol. 47 No. 11/12, pp. 1975-2001.

Zauberman, G., Ratner, R. K., and Kim, B. K. (2009), “Memories as assets: Strategic memory protection in choice over time", Journal of Consumer Research, Vol. 35 No. 5, pp. $715-$ 728. 


\section{Web Appendix A - Study 1 \\ Instruction Texts}

\section{The written instructions given to tellers:}

"In the next phase of this study, you will be assigned to partner with one of the students that went to the other room. The two of you will go into an individual room. In that room, you will see a paper that mentions a topic for you to tell your partner about. Your role is to be the teller. Your partner's role is to be the listener. In this activity, act as you would in a normal conversation with a friend of yours. Be spontaneous, be yourself. In some detail, share with the other student about the topic written on the paper that you will find in the room.

Now that you have finished reading, please wait quietly in this room for further instructions."

\section{The script of the verbal instructions given to conversation partners:}

"In the next phase of this study, you will be assigned to partner with one of the students that stayed in the other room. The two of you will go into a separate room. Your partner will be assigned a topic to tell you about. Your role is to be the listener. When you partner shares with you, react as you would in a regular conversation with a friend. You may react as much or as little, as positively or as negatively as you would like. As you listen, you decide whether you want to ask questions (or not), to clarify a point (or not), to laugh (or not), to agree (or not), to show interest (or not). Just be yourself. Imagine that you are listening to a friend and act accordingly. Do you have questions about what you are going to be doing? " 


\section{Web Appendix B - Study 1 \\ Additional Statistics}

\section{Experiential Purchase}

\begin{tabular}{|l|l|l|l|}
\hline & Pre-Sharing Hap & Post-Sharing Hap & Mean Difference \\
\hline Control Condition & $\mathrm{M}=7.24, \mathrm{SD}=1.75$ & $\mathrm{M}=7.10, \mathrm{SD}=1.61$ & -0.14 \\
\hline Experimental Condition & $\mathrm{M}=6.81, \mathrm{SD}=1.45$ & $\mathrm{M}=7.10, \mathrm{SD}=1.73$ & 0.29 \\
\hline
\end{tabular}

\section{Material Purchase}

\begin{tabular}{|l|l|l|l|}
\hline & Pre-Sharing Hap & Post-Sharing Hap & Mean Difference \\
\hline Control Condition & $\mathrm{M}=6.15, \mathrm{SD}=1.87$ & $\begin{array}{l}\mathrm{M}=6.02, \mathrm{SD}= \\
1.87\end{array}$ & -0.13 \\
\hline Experimental Condition & $\mathrm{M}=5.94, \mathrm{SD}=1.69$ & $\begin{array}{l}\mathrm{M}=6.12, \mathrm{SD}= \\
2.24\end{array}$ & 0.18 \\
\hline
\end{tabular}

The levels of pre-sharing happiness in the control and experimental conditions were statistically indistinguishable for both experiential $(p=.35)$ and material purchase conditions $(p=.68)$. 


\section{Web Appendix C - Study 2}

\section{Manipulation Texts}

\section{Manipulation (Material Purchase Condition)}

Please recall the most recent occasion when you spent about $\$ 50$ to acquire an object. Examples of objects are clothes, furniture, jewelry, and various types of electronic devices.

Describe that object in some detail.

\section{Manipulation (Experiential Purchase Condition)}

Please recall the most recent occasion when you spent about $\$ 50$ to have an experience.

Examples of experiences are vacations, meansl at restaurants, theater performances, and music concerts.

Describe that experience in some detail.

\section{Measurement Items}

\section{Conversational Value $(\alpha=$.95)}

That experience/object makes for a good conversation.

I want to talk to others about that experience/object.

That experience/object is a good topic to talk about.

I feel excited about telling others about my experience/object.

I desire to talk to people about my experience/object.

\section{Purchase-Related Happiness $(r=.69, p<.001)$}

When you think about that experience/object, how happy does it make you?

How much does that experience/object contribute to your happiness in life? 


\section{Web Appendix D - Study 3 \\ Manipulation Texts}

\section{Manipulation of BBQ Grill Framing (Material)}

In this study, we would like you to think about the BBQ grill you own. Grills are something people keep for some time. Naturally, when you purchased it, your goal was that during the time you own the grill, you liked the object. Please recall some details of that object. Make sure you focus on the aspects of the object. Describe specific characteristics of that object and what it is like to have that object.

\section{Manipulation of BBQ Grill Framing (Experiential)}

In this study, we would like you to think about the BBQ grill you own. Grills are something people use for some time. Naturally, when you purchased it, your goal was that during the time you use the grill, you liked the experience of using it. Please recall some details of that experience. Make sure you focus on the aspects of the experience. Describe specific characteristics of that experience and what it is like to have that experience.

\section{Measurement Items}

\section{Conversational Value $(\alpha=.95)$}

That experience/object makes for a good conversation.

I want to talk to others about that experience/object.

That grill is a good topic to talk about.

I desire to talk to people about that experience/object.

I feel excited about telling others about that experience/object.

Purchase-Related Happiness $(r=.74, p<.001)$ 
When you think about that experience/object, how happy does it make you?

How much happiness does that experience/object contribute to your happiness in life? 


\section{Web Appendix E - Seven Replication Studies Study 1 - Past Purchase-American Student Sample}

\section{Procedures}

Ninety-five students from a large American university were asked to recall and describe either an experiential or a material purchase that they had made for about $\$ 50$ and that turned out well (see manipulation text below). Next they responded to two-item measures of conversational value ("I would feel excited about sharing the details of my object", "I would want to share with others the details of my object", $r=.81, p<.001$ ) and purchase-related happiness (the same measure used in the reported studies; $r=.56, p<.001)$.

\section{Results}

An analysis of moderation (PROCESS, model 1), showed significant effects of conversational value on purchase-related happiness for material $(\beta=0.46, \mathrm{SE}=0.11, t(91)=4.18, p<.001$, $95 \% \mathrm{CI}=[0.24,0.67])$ and experiential purchases $(\beta=0.26, \mathrm{SE}=0.12, t(91)=2.07, p=.04$, $95 \% \mathrm{CI}=[0.01,0.51])$. These effects were statistically indistinguishable $(\beta=-0.09, \mathrm{SE}=0.08$, $t(91)=-1.16, p=.24,95 \% \mathrm{CI}=[-0.53,0.13])$.

\section{Manipulation Texts}

Material purchase condition: Please describe, in some detail, a time when you spent about $\$ 50$ on an object. You kept the object for some time and may even still have it. It was an object that you could touch with your hand. You bought the object with the intention of advancing your happiness and enjoyment in life. It turned out well and you did enjoy the purchase.

Experiential purchase condition: Please describe, in some detail, a time when you spent about $\$ 50$ on an experience. In other words, you did not end up with anything tangible (anything you could hold in your hand) at the end of the experience except for your memories. You bought the 
experience with the intention of advancing your happiness and enjoyment in life. It turned out well and you did enjoy the purchase. 


\section{Study 2 - Past Purchase-European Student Sample}

\section{Procedures}

Sixty-seven Master's level business students from a European university recalled and described either a material or an experiential purchase that they had made for about 50 Euros and that turned out well (see manipulation text below). Next they responded to the same measures of conversational value (five-items; $\alpha=.95$ ) and purchase-related happiness (two-items; $r=.64, p<$ $.001)$ as those reported on the paper.

\section{Results}

The data showed a marginally significant effect of conversational value on purchase-related happiness for material purchases $(\beta=0.26, \mathrm{SE}=0.13, t(63)=1.94, p=.05,95 \% \mathrm{CI}=[-0.006$, $0.54])$ and a significant effect for experiential purchases $(\beta=0.48, \mathrm{SE}=0.15, t(63)=3.21, p=$ $.002,95 \% \mathrm{CI}=[0.18,0.78])$; the magnitudes of these effects were statistically indistinguishable $(\beta=0.10, \mathrm{SE}=0.10, t(63)=1.05, p=.29,95 \% \mathrm{CI}=[-0.09,0.31])$.

\section{Manipulation Texts}

Material purchase condition: We sometimes buy material objects. Examples are clothes, furniture, jewelry, and various types of electronic devices. Your task is to recall an object that you purchased for about $50 €$. Your object turned out well. In the following lines, write in some detail about that object.

Experiential purchase condition: We sometimes buy experiences. Examples are vacations, meals at restaurants, theater performances, and music concerts. Your task is to recall an experience that you purchased for about $50 €$. Your experience turned out well. In the following lines, write in some detail about that experience. 


\section{Study 3 - Future Purchase-Mturk Sample}

\section{Procedures}

Eighty-one Mturk participants described either an experiential or a material purchase that they intended to make some time in the future (see manipulation text below). Next they responded to similar measures of conversational value $(r=.91, p<.001)$ and purchase-related happiness $(r=$ $.62, p<.001)$

\section{Results}

The conversational value of material $(\beta=0.40, \mathrm{SE}=0.11, t(77)=0.345, p<.001,95 \% \mathrm{CI}=$ $[0.17,0.64])$ and experiential purchases positively influenced the happiness participants expected to gain from the purchase $(\beta=0.64, \mathrm{SE}=0.13, t(77)=4.92, p<.001,95 \% \mathrm{CI}=[0.38,0.89])$, and the magnitudes of these two effects were statistically indistinguishable $(\beta=0.11, \mathrm{SE}=0.08$, $t(77)=1.33, p=.18,95 \% \mathrm{CI}=[-0.05,0.29])$.

\section{Manipulation Texts}

Material purchase condition: We would like you to please think and write, in some detail, about an object that you intend to purchase some time in the future. In other words, write about a material purchase that you think about making. Such purchase is something tangible, something you can touch with your hand. When writing, please describe the object itself and what you imagine it will be like to have it.

Experiential purchase condition: we would like you to please think and write, in some detail, about an experience that you intend to purchase some time in the future. In other words, write about an experiential purchase that you think about making. Such purchase is something you experience or live through, and that at the end of it all you are left with are your memories of it. 
When writing, please describe the experience itself and what you imagine it will be like to have it. 


\section{Study 4 - BBQ Framing-European Student Sample}

\section{Procedures}

Seventy-seven Master's level business students from a European university were asked to imagine purchasing a BBQ grill, which was framed as a material or an experiential purchase. Next they completed the five-item measure of conversational value $(\alpha=.95)$ and the two-item measure of purchase-related happiness $(r=.76, p<.001)$.

\section{Results}

The conversational value of material $(\beta=0.57, \mathrm{SE}=0.14, t(73)=3.84, p<.001,95 \% \mathrm{CI}=$ $[0.27,0.86])$ and experiential purchases positively influenced purchase-related happiness $(\beta=$ $0.51, \mathrm{SE}=0.16, t(73)=3.18, p=.002,95 \% \mathrm{CI}=[0.19,0.83])$ at statistically indistinguishable levels $(\beta=-0.05, \mathrm{SE}=0.21, t(73)=-0.27, p=.78,95 \% \mathrm{CI}=[-0.49,0.37])$

\section{Manipulation Texts}

Material framing condition: In this study, we would like you to imagine that you bought a BBQ grill. You kept that object for some time and may still have it. In some detail, please describe that object. Focus on the characteristics of the object and on what it is like to have that object.

Experiential framing condition: In this study, we would like you to imagine that you bought a BBQ grill. You used it for some time and may still use it. In some detail, please describe the experience of using it. Focus on the characteristics of the experience and on what it is like to have that experience. 


\section{Study 5 - Purchase Valence-Mturk Sample}

\section{Procedures}

Two hundred and eighty-one Mturk participants were randomly assigned to one experimental condition of this 2 (purchase type: experiential vs. material) by 2 (purchase valence: positive vs. negative) between-subjects study. After writing about a past experiential or material purchase that turned out positive or negatively (Nicolao et al., 2009), participants completed the assessments of conversational value (five-item; $\alpha=.95$ ) and happiness (two-item; $r=.79, p<$ $.001)$

\section{Results}

Results showed that, across valence, conversational value had a positive effect on purchaserelated happiness for material $(\beta=0.73, \mathrm{SE}=0.07, t(277)=0.94, p<.001,95 \% \mathrm{CI}=[0.58, .89])$ and experiential purchases $(\beta=0.78, \mathrm{SE}=0.06, t(277)=12.12, p<.001,95 \% \mathrm{CI}=[0.65,0.91])$, and the magnitudes of the effects were statistically indistinguishable $(\beta=0.04, \mathrm{SE}=0.10, t(277)$ $=0.49, p=.62,95 \% \mathrm{CI}=[-0.14,0.24])$. In the positive and negative valence conditions, the conversational value of both purchases types (material and experiential) influenced purchaserelate happiness (all $p \mathrm{~s}<.001)$. In the positive valence condition, the effect was significantly stronger for experiential (vs. material) purchases $\left(p_{\text {interaction }}=.01\right)$. In the negative valence condition the effects were statistically indistinguishable $(p$ interaction $=.60)$.

\section{Manipulation Texts}

Material purchase_positive valence condition: Please recall a time when you spent about $\$ 50$ on an object. Examples of objects are clothes, furniture, jewelry, and various types of electronic devices. You bought the object to increase your happiness. It turned out well and you did enjoy the purchase. 
Describe that object in some detail.

Experiential purchase_-positive valence condition: Please recall a time when you spent about $\$ 50$ on an experience. Examples of experiences are vacations, meals at restaurants, theater performances, and music concerts. You bought the experience to increase your happiness. It turned out well and you did enjoy the purchase.

Describe that experience in some detail.

Material purchase_-negative valence condition: Please recall a time when you spent about $\$ 50$ on an object. Examples of objects are clothes, furniture, jewelry, and various types of electronic devices. You bought the object to increase your happiness. Unfortunately, it did not turn out well and you did not enjoy the purchase.

Describe that object in some detail.

Experiential purchase—negative valence condition: Please recall a time when you spent about $\$ 50$ on an experience. Examples of experiences are vacations, meals at restaurants, theater performances, and music concerts. You bought the experience to increase your happiness. Unfortunately, it did not turn out well and you did not enjoy the purchase.

Describe that experience in some detail. 


\section{Study 6 - Solo vs. Social Consumption-American Student Sample}

\section{Procedures}

One hundred and seventeen students from a large American university participated in this 2 (purchase type: experiential vs. material) by 2 (sociality of the consumption: solo vs. social) between-subjects study. They first wrote about an experiential or material purchase that they had consumed alone or in the company of somebody else. Next they answered two-item measures of conversational value $(r=.41, p<.001)$ and purchase-related happiness $(r=.53, p<.001)$.

\section{Results}

The data showed that across sociality of the consumption, conversational value exerted a positive impact on purchase-related happiness for both material $(\beta=0.30, \mathrm{SE}=0.13, t(113)=2.30, p=$ $.02,95 \% \mathrm{CI}=[0.04,0.56])$ and experiential purchases $(\beta=0.63, \mathrm{SE}=0.13, t(113)=4.72, p<$ $.001,95 \% \mathrm{CI}=[0.36,0.90])$, and that the magnitudes of these effects were statistically indistinguishable $(\beta=0.33, \mathrm{SE}=0.18, t(113)=1.76, p=.08,95 \% \mathrm{CI}=[-0.04,0.70])$. The simple effects are also indistinguishable when the two sociality of the consumption conditions are analyzed separately.

\section{Manipulation Texts}

Material purchase—solo condition: Please describe, in some detail, a time when you spent about $\$ 50$ on an object. You kept the object for some time and may even still have it. It was an object that you could touch with your hand. You used/consumed this object by yourself, not with anybody else.

Experiential purchase—solo condition: Please describe, in some detail, a time when you spent about $\$ 50$ on an experience. In other words, you did not end up with anything tangible (anything 
you could hold in your hand) at the end of the experience except for your memories. You had that experience by yourself, not with anybody else.

Material purchase—social condition: Please describe, in some detail, a time when you spent about $\$ 50$ on an object. You kept the object for some time and may even still have it. It was an object that you could touch with your hand. You used/consumed this object together with other people whom you knew or became acquainted with during the use/enjoyment of the object. Experiential purchase—social condition: Please describe, in some detail, a time when you spent about $\$ 50$ on an experience. In other words, you did not end up with anything tangible (anything you could hold in your hand) at the end of the experience except for your memories. You had that experience together with other people whom you knew or became acquainted with during the use/enjoyment of the experience. 


\section{Study 7 - Solo vs. Social Consumption-Mturk Sample}

\section{Procedures}

Three hundred and thirty-five Mturk participants were randomly assigned to one experimental condition of this 2 (purchase type: experiential vs. material) by 2 (sociality of the consumption: solo vs. social) between-subjects study. They first wrote about an experiential or material purchase that they had consumed alone or in the company of somebody else. Next they answered the measures of conversational value (five-item; $\alpha=.94)$ and purchase-related happiness $(r=.68$, $p<.001)$

\section{Results}

Results indicateed that, across sociality of the consumption, purchase-related happiness was positively influenced by the conversational value of both material $(\beta=0.56, \mathrm{SE}=0.05, t(331)=$ $9.66, p<.001,95 \% \mathrm{CI}=[0.45,0.68])$ and experiential purchases $(\beta=0.53, \mathrm{SE}=0.06, t(331)=$ $8.04, p<.001,95 \% \mathrm{CI}=[0.40,0.66])$. These effects were statistically indistinguishable $(\beta=$ $-0.03, \mathrm{SE}=0.08, t(331)=-0.39, p=.69,95 \% \mathrm{CI}=[-0.20,0.13])$. Results are the same at each level of sociality of the consumption.

\section{Manipulation Texts}

Material purchase—solo condition: Please describe, in some detail, a time in the last 12 months when you spent about $\$ 50$ on an object. You kept the object for some time and may still have it. It was an object that you could touch with your hand. You bought the object with the intention of advancing your happiness and enjoyment in life. It turned out well and you did enjoy the purchase. You used/consumed this object by yourself, not with anybody else.

Experiential purchase — solo condition: Please describe, in some detail, a time in the last 12 months when you spent about $\$ 50$ on an experience. In other words, you did not end up with 
anything tangible (anything you could touch with your hand) at the end of the experience except for your memories. You bought the experience with the intention of advancing your happiness and enjoyment in life. It turned out well and you did enjoy the purchase. You had that experience by yourself, not with anybody else.

Material purchase—social condition: Please describe, in some detail, a time in the last 12 months when you spent about $\$ 50$ on an object. You kept the object for some time and may still have it. It was an object that you could touch with your hand. You bought the object with the intention of advancing your happiness and enjoyment in life. It turned out well and you did enjoy the purchase. You used/consumed this object together with other people whom you knew or became acquainted with during the use/enjoyment of the object.

Experiential purchase — social condition: Please describe, in some detail, a time in the last 12 months when you spent about $\$ 50$ on an experience. In other words, you did not end up with anything tangible (anything you could touch with your hand) at the end of the experience except for your memories. You bought the experience with the intention of advancing your happiness and enjoyment in life. It turned out well and you did enjoy the purchase. You had that experience together with other people whom you knew or became acquainted with during the use/enjoyment of the experience. 